\title{
Catgut Implantation at Baliao and Xingfu One Acupuncture Point to Treat Dysdefecation in Patients with Incomplete Spinal Cord Injury: Three Cases Report
}

\author{
Qingqing Li1 ${ }^{*}$, Laiming Yu², Hui Chen1, Ruzhi Zhang³, Xinghua Yang4, Qiuling Liu, \\ Maping Huang1, Dahui Zhang1, Shuqing Wu ${ }^{1}$
}

\footnotetext{
${ }^{1}$ Department of Neurourological Rehabilitation, Guangdong Provincial Work Injury Rehabilitation Hospital, Guangzhou, China ${ }^{2}$ Guangzhou Southern Mingdao Modified Acupuncture and Moxibustion Catgut Embedding Promotion Center, Guangzhou, China

${ }^{3}$ Subhealth Center, Guangdong Provincial Work Injury Rehabilitation Hospital, Guangzhou, China

${ }^{4}$ Department of Spine and Spinal Cord Injury Rehabilitation, Guangdong Provincial Work Injury Rehabilitation Hospital, Guangzhou, China

Email: *guangzhoulqq@163.com
}

How to cite this paper: Li, Q.Q., Yu, L.M., Chen, H., Zhang, R.Z., Yang, X.H., Liu, Q.L., Huang, M.P., Zhang, D.H. and Wu, S.Q. (2020) Catgut Implantation at Baliao and Xingfu One Acupuncture Point to Treat Dysdefecation in Patients with Incomplete Spinal Cord Injury: Three Cases Report. Open Journal of Urology, 10, 211-216. https://doi.org/10.4236/oju.2020.106024

Received: Aril 14, 2019

Accepted: June 21, 2020

Published: June 24, 2020

Copyright $\odot 2020$ by author(s) and Scientific Research Publishing Inc. This work is licensed under the Creative Commons Attribution International License (CC BY 4.0).

http://creativecommons.org/licenses/by/4.0/ (c) (i) Open Access

\begin{abstract}
Objective: To probe into the effect of catgut implantation at Baliao and Xingfu One Acupuncture Point on dysdefecation in patients with incomplete spinal cord injury (SCI). Methods: Three SCI patients voluntarily accepted catgut embedding at Baliao and Xingfu One Acupuncture point. Before and after treatment, they were filled out the self-rating scale of defecation, including the data of defecation frequency, total defecation time, defecation effort, fecal texture, fecal characteristics and fecal incontinence, etc. Results: Compared with the baseline data, constipation was improved and fecal incontinence was disappeared. Conclusions: Catgut implantation at Baliao and Xingfu One Acupuncture Point is effectual for patients with neurogenic dysporia secondary to incomplete SCI.
\end{abstract}

\section{Keywords}

Baliao, Xingfu One Acupuncture Point, Catgut Implantation, Spinal Cord Injury, Dysdefecation

\section{Case Report}

Sacral neuromodulation is a low-frequency electric pulse regulation technique of 
sacral nerve using interventional technique. SNM is not only used for refractory Overactive Bladder, idiopathic urinary retention [1] [2], fecal incontinence [3], but also has some effects on neurogenic bladder [4], chronic constipation [5]. However, it has the disadvantage, such as high price, complicated operation, radioactive and postoperative infection and so on. It is the common task of Urology, neurology, rehabilitation medicine and multi-professional team to find a more simple, effective and cheap treatment. How to make SNM further convenient and more acceptable to patients? Apart from SNM, is the pudendal nerve touch feasible? What is the relationship between them? In our previous clinical studies, it has been confirmed the effectiveness of Catgut Implantation at Baliao and Xingfu One Acupuncture Point for urinary incontinence in patients with incomplete SCI [6]. Then whether this treatment is effective for defecation disorders in patients with incomplete SCI? Presently reports are as follows.

2018-2019, three cases with dysdefecation secondary to incomplete spinal cord injury (SCI) were collected (Table 1). They were assessed the clinical efficacy score of defecation (self-assessment) before and after treatment (Table 2).

All patients signed informed consent before per treatment. They accepted catgut embedding at bilateral Baliao, Xingfu One Acupuncture points for three times (an interval of 14 days). Four pairs of posterior sacral foramen are called Baliao (green marker); Xingfu One Acupuncture point is the same level as the fourth posterior sacral foramen and it is close to the lateral edge of the sacrum (red one) (Figure 1).

Figure 2 showed disposable acupoint catgut embedding assistant package and syringe needle (Figure 2).

All patients were not allowed to bathe within 24 hours after therapy. No spicy and irritating foods were permitted to eat within 3 days after catgut embedding. Before and after the remedy, they recorded the data of defecation frequency, total defecation time, defecation effort, fecal texture, characteristics and incontinence, etc. Compared to the baseline data, constipation was improved and fecal incontinence was disappeared (Tables 3-5), (Figure 3).

No related adverse events were found. The informed consent was obtained from all subjects to report the cases.

\section{Discussion}

From Table 3, we can see that, except fecal characteristics, three patients' sub-scores of clinical effect after treatment were lower than that before treatment. Table 4 and Figure 3 indicate that each patient' total score of clinical effect after therapy is also lower than that before therapy. In Table 3, the most significant change is fecal incontinence: This is closely related to the first patient. Before catgut embedding, the frequency of fecal incontinence of this patient is less than or equal to 1 time/week, and after catgut embedding, fecal incontinence disappears. See Table 5 for details. The score of fecal characteristics slightly increased, indicated that in general, the stool of patients after treatment tends to be softer. 


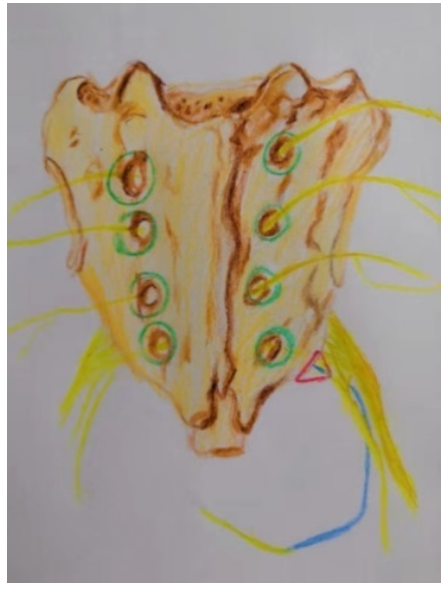

Figure 1. Anatomical sketch of Baliao and Xingfu One Acupuncture point.
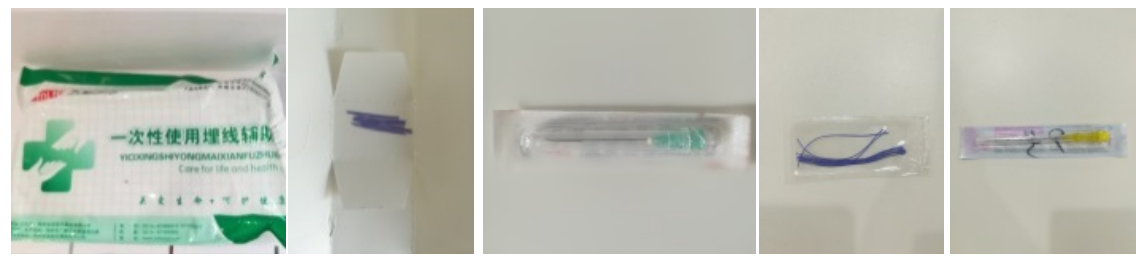

Figure 2. Appliances of catgut embedding.

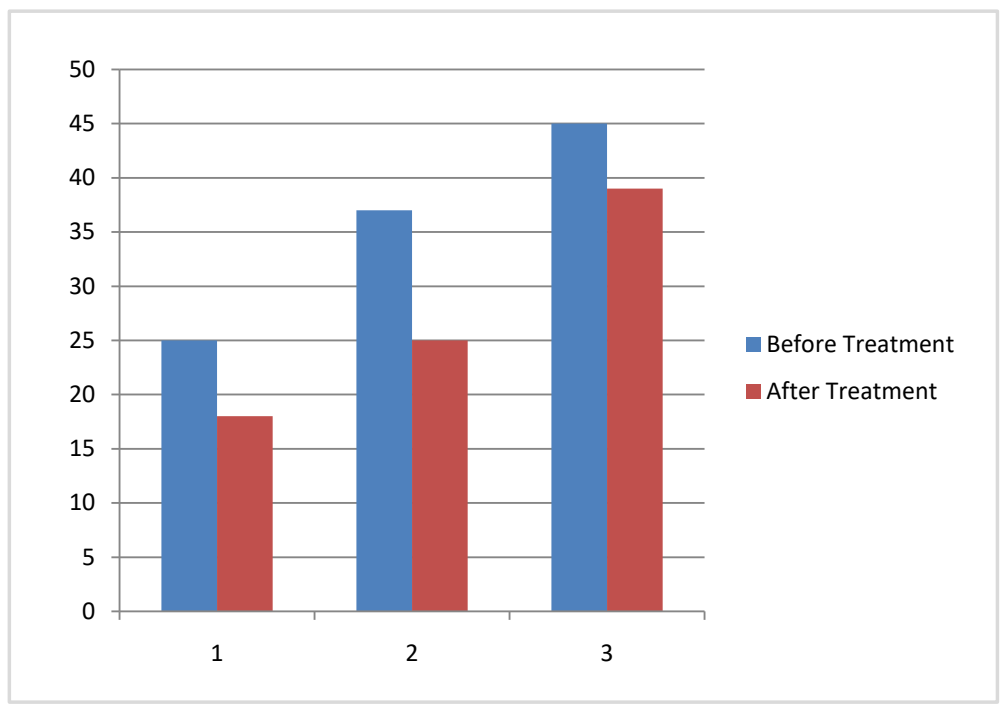

Figure 3. Changes in total score of clinical effect on defecation in 3 patients before and after treatment.

Table 1. Baseline characteristics of the cases.

\begin{tabular}{lllllll}
\hline Number & Gender & Age (y) $\begin{array}{l}\text { Duration } \\
\text { of SCI (y) }\end{array}$ & Disease & Constipation & $\begin{array}{l}\text { Fecal } \\
\text { Incontinence }\end{array}$ \\
\hline 1 & F & 37 & 2 & SCI (C4 AIS Grade D) & Yes & Yes \\
2 & F & 19 & 2 & Cauda Equina Syndrome Yes & No \\
3 & M & 36 & 1 & SCI (T10 AIS Grade C) & Yes & No \\
\hline
\end{tabular}


Table 2. Clinical efficacy score of defecation.

\begin{tabular}{|c|c|c|c|c|c|}
\hline & 0 & 3 & 5 & 7 & score \\
\hline \multicolumn{6}{|l|}{ Defecation } \\
\hline $\begin{array}{l}\text { Frequency } \\
\text { (times/day) }\end{array}$ & 1 day once & 2 - 3 days once & \multicolumn{3}{|c|}{4 - 5 days once $>5$ days once } \\
\hline $\begin{array}{l}\text { Total Defecation } \\
\text { Time (min) }\end{array}$ & $<15$ mins & 15 - 30 mins & $30-60$ mins & $>60$ mins & \\
\hline Defecation Effort & easy & slightly difficult & more difficult & hard & \\
\hline Fecal texture & soft & slightly hard & hard & Very hard & \\
\hline \multirow[b]{2}{*}{$\begin{array}{l}\text { Fecal } \\
\text { Characteristics }\end{array}$} & $\begin{array}{l}\text { Dispersing hard } \\
\text { blocks, }\end{array}$ & $\begin{array}{l}\text { Dry hard block, } \\
\text { Surface Crack }\end{array}$ & $\begin{array}{l}\text { Clear-Cut } \\
\text { Margin, }\end{array}$ & $\begin{array}{l}\text { marginal } \\
\text { indistinctness }\end{array}$ & \\
\hline & $\begin{array}{l}\text { Similar to hard } \\
\text { block or granular }\end{array}$ & $\begin{array}{l}\text { Smooth and Soft, } \\
\text { Like Sausage } \\
\text { (Banana) }\end{array}$ & Soft Cluster & Paste Like & \\
\hline $\begin{array}{l}\text { rectum mucosa } \\
\text { protector } \\
\text { (Glycerin) }\end{array}$ & No & 0.5 - 1 drug a day & $\begin{array}{l}2 \text { - } 3 \text { drugs } \\
\text { a day }\end{array}$ & $>4$ drugs a day & \\
\hline $\begin{array}{l}\text { Manual } \\
\text { Dilatation }\end{array}$ & No & $<5$ turns & $5-10$ turns & $>10$ turns & \\
\hline Hand digging & No & sonce/week & $\begin{array}{l}2 \text { - } 3 \text { times/ } \\
\text { week }\end{array}$ & $>3$ times/week & \\
\hline $\begin{array}{l}\text { Fecal } \\
\text { incontinence }\end{array}$ & No & sonce/week & $\begin{array}{l}2 \text { - } 3 \text { times/ } \\
\text { week }\end{array}$ & $>3$ times/week & \\
\hline
\end{tabular}

Table 3. Changes in sub-scores of clinical effect in 3 patients before and after therapy.

\begin{tabular}{ccc}
\hline \multirow{2}{*}{ Item } & \multicolumn{2}{c}{ Arithmetic mean \pm Standard deviation } \\
\cline { 2 - 3 } & Before therapy & After therapy \\
\hline Defecation Frequency (times/day) & $2.00 \pm 1.73$ & $1.00 \pm 1.73$ \\
Total Defecation Time (min) & $4.33 \pm 1.15$ & $3.67 \pm 1.15$ \\
Defecation Effort & $5.67 \pm 1.15$ & $4.33 \pm 2.31$ \\
Fecal texture & $5.00 \pm 0.00$ & $3.67 \pm 1.15$ \\
Fecal Characteristics & $3.33 \pm 2.89$ & $3.67 \pm 1.15$ \\
mucosa protector (Glycerin) & $3.67 \pm 1.15$ & $3.00 \pm 0.00$ \\
Manual Dilatation & $3.33 \pm 2.89$ & $2.00 \pm 1.73$ \\
Hand digging & $5.67 \pm 2.31-$ & $4.67 \pm 4.04$ \\
fecal incontinence & $1.00 \pm 1.73$ & $0.00 \pm 0.00$
\end{tabular}

Table 4. Changes in total score of clinical effect in 3 patients before and after treatment.

\begin{tabular}{ccc}
\hline Number & Before treatment & After treatment \\
\hline 1 & 25 & 18 \\
2 & 37 & 39 \\
3 & 45 & 25 \\
Arithmetic mean \pm Standard deviation & $35.67 \pm 10.07$ & $27.33 \pm 10.69$ \\
\hline
\end{tabular}


Table 5. Changes in fecal incontinence of 3 cases before and after therapy.

\begin{tabular}{ccc}
\hline Number & Before therapy & After therapy \\
\hline 1 & 3 & 0 \\
2 & 0 & 0 \\
3 & 0 & 0 \\
\hline
\end{tabular}

Baliao (BL 31-34), lies in four pairs of posterior sacral foramen, it is equal to the Sacral Jiaji Point. The reinforcing stimulation of the above target region on the sacral nerve can promote function recovery of the intestinal nervous system and the autonomic nervous one. Through the action relationship of Brain-gut Axis, Regulate the somatic-visceral reflex, the afferent of sensory signals, the activity of internal and external anal sphincter. Patients can reduce the colonic transit time, enhance the contractility of the intestine, increase the secretion of the intestinal fluid, boost the coordination of pelvic floor muscles, etc., so as to improve the defecation [7] [8] [9]. Because of its unique characteristics in the remedy of urogenital diseases, pelvic floor anorectal ones and so forth, it had been highly praised by doctors through the ages, especially for its obvious effect of Zhongliao (BL 33), Ciliao (BL 32). Historically, There is a widespread clinical application [10] [11] [12].

Xingfu One Acupuncture Point is about $6 \mathrm{~cm}$ deep from the surface of the body, it is even with the Fourth sacral posterior foramen and it is three transverse fingers (ring, middle and index finger) away from the sacral median ridge. This is extra nerve point. It has a good curative effect by touching pudendal nerve in treating anorectal or urinary [6] or sexual dysfunction, gynecology and other diseases.

Acupoint catgut embedding achieves therapeutic aim by stimulating acupuncture points for a long time. This therapy is safe, simple, cheap and well-compliant. It is worthy of clinical research, application and promotion. This case report shows that, after catgut implantation, the patients' constipation and fecal incontinence were significantly improved. The two groups of acupoints act on mutual promotion and synergistic effect. It is a simple and easy Chinese-style therapy of "sacral nerve regulation" and "pudendal nerve touch".

\section{Conclusion}

Catgut Implantation at Baliao and Xingfu One Acupuncture Point is effective for dysdefecation secondary to incomplete SCI.

\section{Acknowledgements}

I sincerely thank Dr. Laiming Yu, Dr. Ruzhi Zhang, Dr. Hui Chen and other colleagues for their strong assistance and support in this study.

\section{Conflicts of Interest}

The authors declare no conflicts of interest regarding the publication of this paper. 


\section{References}

[1] van Kerrebroeck, P.E., van Voskuilen, A.C., Heesakkers, J.P., et al. (2007) Results of Sacral Neuromodulation Therapy for Urinary Voiding Dysfunction: Outcomes of a Prospective, Worldwide Clinical Study. Journal of Urology, 178, 2029-2034. https://doi.org/10.1016/j.juro.2007.07.032

[2] Gormley, E.A., Lightner, D.J., Burgio, K.L., et al. (2012) Diagnosis and Treatment of Overactive Bladder (Non-Neurogenic) in Adults: AUA/SUFU Guideline. Journal of Urology, 188, 2455-2463. https://doi.org/10.1016/j.juro.2012.09.079

[3] Abrams, P., Andersson, K.E., Birder, L., et al. (2010) Fourth International Consultation on Incontinence Recommendations of the International Scientific Committee: Evaluation and Treatment of Urinary Incontinence, Pelvic Organ Prolapse, and Fecal Incontinence. Neurourology and Urodynamics, 29, 213-240. https://doi.org/10.1002/nau.20870

[4] Wang, Y. and Hassouna, M.M. (2000) Neuromodulation Reduces c-fos Gene Expression in Spinalized Rats: A Double-Blind Randomized Study. Journal of Urology, 163, 1966-1970. https://doi.org/10.1097/00005392-200006000-00103

[5] Thomas, G.P., Dudding, T.C., Rahbour, G., et al. (2013) Sacral Nerve Stimulation for Costipation. British Journal of Surgery, 100, 174-181. https://doi.org/10.1002/bjs.8944

[6] Li, Q.Q., Yu, L.M., Chen, H., et al. (2019) Catgut Implantation at Baliao and Xingfu One Acupuncture Point to Treat Urinary Incontinence in Patients with Incomplete Spinal Cord Injury: Three Cases Report. Open Journal of Urology, 9, 115-118. https://doi.org/10.4236/oju.2019.98014

[7] Zhang, B., Zheng, J.Y., Cui, L., et al. (2018) Observation to the Effect of Sacral Nerve Stimulation on the Autonomic Nervous Function of Chronic Functional Constipation. Chinese Journal of Colorectal Disease, 7, 552-556.

[8] Qu, M.W., Li, G.D., Hong, Z.F., et al. (2013) Clinical Observation on Baliao Acupoints Catgut Embedding for 30 Cases of Slow Transit Constipation. Journal of Traditional Chinese Medicine, 19, 1663-1665.

[9] Wang, L.T., Jiang, Y.M., Zhan, H.S., et al. (2016) Clinical Observation on the Treatment of Fecal Incontinence in Patients with Spinal Cord Injury by Acupuncture at Baliao Point Combined with Electroacupuncture. Acta Chinese Medicine and Pharmacology, 44, 61-64.

[10] Kenefick, N.J., Vaizey, C.J., Cohen, C.R., et al. (2002) Double-Blind Placebocontrolled Crossover Study of Sacral Nerve Stimulation for Idiopathic Constipation. British Journal of Surgery, 89, 1570-1571. https://doi.org/10.1046/j.1365-2168.2002.02278.x

[11] Holzer, B., Rosen, H.R., Novi, G., et al. (2008) Sacral Nerve Stimulation in Patients with Severe Constipation. Diseases of the Colon \& Rectum, 51, 524-530. https://doi.org/10.1007/s10350-007-9160-9

[12] Kuang, X.H. and Kang, Y.W. (2018) Clinical Observation of Electrical-Warmed Acupuncture of Baliao Point in the Treatment of Neurogenic Bladder after Spinal Cord Injury. Journal of Emergency in Traditional Chinese Medicine, 27, 2017-2020. 